\title{
Effects of prednisone on urinary proteome and disease biomarkers in a rat model
}

\begin{abstract}
Urine is a good biomarker source for proteomics studies, but several factors may affect the urine proteome. To evaluate the possible impact of glucocorticoids drugs on the urine proteome, we investigated the effects of prednisone on urine proteome in a rat model. Urine samples were collected from control and prednisone-treated rats after drug administration. The urinary proteome was analyzed using liquid chromatographytandem mass spectrometry (LC-MS/MS), and proteins were identified using label-free proteome quantification. A total of 523 urinary proteins were identified in rat urine. Using label-free quantification, 27 urinary proteins showed differential abundances after prednisone treatment. A total of 16 differential proteins and/or their human orthologs have been previously reported as disease biomarkers. Two differential proteins (Haptoglobin and Neutrophil collagenase) were validated via Western blot. After functional analysis, it was found that the pharmacological effects of prednisone were reflected in the urine. Prednisone treatment influences urine proteome and some disease biomarkers, and it should be taken into consideration in future disease biomarker studies.
\end{abstract}

Keywords: urine, proteomics, biomarkers, prednisone, drug treatment
Volume 6 Issue 2 - 2017

\author{
Jianqiang Wu,' Xundou Li, 'Youhe Gao \\ 'Department of Pathophysiology, Peking Union Medical College, \\ China \\ ${ }^{2}$ Department of Biochemistry and Molecular Biology, Beijing \\ Normal University, China
}

Correspondence: Youhe Gao, Department of Pathophysiology, Peking Union Medical College, China, Tel 86I058804382, Email gaoyouhe@bnu.edu.cn

Received:September 18,2017 | Published: October 06, 2017

\section{Introduction}

Disease biomarkers are measurable changes associated with specific pathophysiological conditions that can be used to diagnose and monitor diseases, to predict prognoses and to reflect treatment efficiency. As a non-invasively accessible and relatively stable liquid, urine is a promising clinical sample source for biomarker discovery via proteomics approaches. ${ }^{1}$ Recently, urinary proteomics has received increasing attention in disease biomarker research.

Urinary proteins mainly originate from the urinary system, and the remaining proteins are plasma proteins derived from glomerular filtration. ${ }^{2}$ Currently, in addition to its extensive application in urogenital diseases, urinary proteomics have been applied to a wide range of non-urogenital diseases to exploit urinary disease biomarkers, such as cancers, cardiovascular diseases, and mental disorders, among others. However, challenges still remain in the urine biomarker discovery field. Urine is sensitive and may be affected many factors, ${ }^{1}$ such as gender, ${ }^{3}$ age, ${ }^{4}$ menstrual cycle, ${ }^{5}$ exercise,${ }^{6}$ and smoking. ${ }^{7}$ Therefore, it is difficult to definitively determine whether potential biomarkers identified are truly related to disease.

In clinical practice, drugs can reverse disease processes and are very likely to have a significant impact on the urinary proteome and related disease biomarkers. However, due to ethical issues, it is impossible to halt drug treatment in patients during urine collection. Drugs have both therapeutic effects and side effects. Therapeutic effects cure the disease and might reduce or even eliminate disease biomarkers, whereas side effects create changes unrelated to the disease biomarker that might erroneously be considered disease biomarkers if the drug effect is not considered in a biomarker study. Knowing the impact of drugs on the urine proteome can help eliminate interference when detecting real disease biomarkers in urine.

As widely prescribed drugs, glucocorticoids are currently used to treat a wide range of diseases based on their potent anti- inflammatory, immunosuppressive and anti-neoplastic effects. One previous report indicated that approximately $0.9 \%$ of the population is using glucocorticoids at any given time. ${ }^{8}$ Among glucocorticoids, prednisone is a commonly prescribed drug that can induce an overall catabolic protein response. ${ }^{9}$ Despite the high prevalence of prednisone use in clinical practice and its strong association with protein metabolism, the effects of prednisone treatment on the urinary proteome remain unknown, which might hamper biomarker discovery for numerous diseases. In this study, an animal model was used to limit the number of confounding factors and enable observation of associated changes from fewer samples. To evaluate the possible impact of prednisone administration on the urinary proteome and related disease biomarkers, this study performed urinary proteomics analysis using LC-MS/MS in a rat model.

\section{Materials and methods}

\section{Experimental animals and drug administration}

This study was performed on twelve male Sprague-Dawley rats (approximately $220 \mathrm{~g}$ ) obtained from the Institute of Laboratory Animal Science, Chinese Academy of Medical Science. The animals were housed in cages with six rats per cage, fed a standard laboratory diet, and provided water ad libitum. All of the rats were housed under controlled indoor temperature $\left(221^{\circ} \mathrm{C}\right)$ and humidity $(65-70 \%)$ conditions. All of the experimental protocols were reviewed and approved by Institute of Basic Medical Sciences Animal Ethics Committee, Peking Union Medical College (ID: ACUC-A02-2014-007).

After acclimatization for 3 days in cages, the rats were randomly divided into two groups. In the prednisone-treated group, rats were daily administered a prednisone solution $(2 \mathrm{mg} / \mathrm{ml})$ at $4 \mathrm{mg} / \mathrm{kg} / \mathrm{day}$ via oral gavage. In the control group, rats were given a matching volume of sterile saline by intragastric administration. The rats in the prednisone group received medication every $24 \mathrm{~h}$ for 2 weeks. 


\section{Urine collection and sample preparation}

Urine samples were collected from all of the rats on days 7 and 14 after the animals were individually placed in metabolic cages. The rats had free access to water but no food to avoid sample contamination during urine collection. Urine was collected within $8 \mathrm{~h}$ of intragastric administration, and the urine volumes were measured. After collection, the urine was immediately centrifuged at $12,000 \mathrm{~g}$ for $20 \mathrm{~min}$ at $4^{\circ} \mathrm{C}$. Urinary proteins were extracted with ethanol overnight followed by centrifugation at $12,000 \mathrm{~g}$ for $20 \mathrm{~min}$. The precipitate was then resuspended in lysis buffer ( $8 \mathrm{M}$ urea, $2 \mathrm{M}$ thiourea, $50 \mathrm{mM}$ Tris and $25 \mathrm{mM}$ DTT). Sample aliquots were stored at $-80^{\circ} \mathrm{C}$ for later proteomics analysis. The urine after gavage was used for subsequent laboratory biochemical analysis. The creatinine and urea nitrogen concentrations in the urine were measured at the clinical laboratory of the Peking Union Medical College Hospital.

\section{Protein digestion}

Urine samples from ten rats in two groups after gavage on day 14 were randomly selected ( 5 rats in each group). The urinary proteins were prepared using the filter-aided sample preparation method Wisniewski et al. Briefly, after $100 \mu \mathrm{g}$ of protein from an individual sample was denatured with $20 \mathrm{mM}$ dithiothreitol at $37^{\circ} \mathrm{C}$ for $1 \mathrm{~h}$ and alkylated with $50 \mathrm{mM}$ iodoacetamide in the dark for $40 \mathrm{~min}$, the samples were loaded onto filter devices with a cut-off of $10 \mathrm{kD}$ (Pall, Port Washington, NY, USA) and centrifuged at $14,000 \mathrm{~g}$ at $18^{\circ} \mathrm{C}$. Then, after washing twice with UA ( $8 \mathrm{M}$ urea in $0.1 \mathrm{M}$ Tris- $\mathrm{HCl}, \mathrm{pH} 8.5)$ and four times with $25 \mathrm{mM} \mathrm{NH} 4 \mathrm{HCO} 3$, the samples were re-dissolved in $25 \mathrm{mM} \mathrm{NH} 4 \mathrm{HCO} 3$ and digested with trypsin (enzyme to protein ratio of $1: 50$ ) at $37^{\circ} \mathrm{C}$ overnight. The peptide mixtures were desalted and dried by vacuum evaporation.

\section{LC-MS/MS analysis}

The peptide samples were re-dissolved in $0.1 \%$ formic acid to a concentration of $0.5 \mu \mathrm{g} / \mu \mathrm{L}$. For analysis, $1 \mu \mathrm{g}$ of peptide were loaded on a trap column and were separated on a reverse-phase $\mathrm{C} 18$ analytical column using the EASY-nLC 1200 HPLC system. The elution for the analytical column was over $120 \mathrm{~min}$ at a flow rate of $300 \mathrm{~nL} / \mathrm{min}$. Then, the peptides were analyzed with an Orbitrap Fusion Lumos Tribrid mass spectrometer (Thermo Fisher Scientific, Waltham, MA, USA). MS data were acquired in high-sensitivity mode using the following parameters: data-dependent MS/MS scans per full scan with top-speed mode (3 s), MS/MS scans at a resolution of 30000 in Orbitrap, 30\% HCD collision energy, charge-state screening (including precursors with a charge state of +2 to +7 ), dynamic exclusion (exclusion duration $30 \mathrm{~s}$ ) and a maximum injection time of $45 \mathrm{~ms}$. Two technical replicate analyses were performed for each individual sample.

\section{Label-free quantification}

Label-free quantitation of the proteomic data was performed using Progenesis LC-MS software (version 4.1, Nonlinear, Newcastle upon Tyne, UK). Twenty sample features (ten samples with two technical replicates) were aligned according to their retention times, and peptides with charge states of +2 to +4 were selected in the analysis. The peak lists were exported, and the data were searched against the SwissProt rat database (Released in July 2014; containing 7,906 sequences) using Mascot software (version 2.5.1, Matrix Science, London, UK). The parent ion tolerance was set at $10 \mathrm{ppm}$, and the fragment ion mass tolerance was set to $0.05 \mathrm{Da}$. A maximum of two missed cleavage sites in the trypsin digestion was allowed. Carbamidomethylation of cysteines was set as a fixed modification, and the oxidation of methionine was considered a variable modification. For protein quantification, the total cumulative abundance of a specific protein was calculated by summing the individual abundances of unique peptides. Comparisons across different samples were performed after normalization of protein abundance using Progenesis LC-MS software.

\section{Bioinformatics analysis and biomarker filtering}

After label-free quantization, the differential proteins were screened for a fold change $>1.5$ and $p$ value $<0.05$ between the two groups. The differentially expressed proteins were further analyzed using IPA software (Ingenuity Systems, Mountain View, CA). This analysis was used to interpret the differentially expressed proteins based on the canonical pathways, interaction networks and disease mechanisms that the proteins were expected to regulate.

The biomarker filter function in the IPA software was used to filter disease biomarkers. Additionally, we identified the human orthologs of the differentially expressed proteins using BLAST (http://www. uniprot.org/blast/). The Urinary Protein Biomarker Database is a literature curated database of protein biomarkers that have been detected in urine (Shao et al., 2011). These differentially expressed proteins and their human orthologs were searched using the Urinary Protein Biomarker Database (http://www.urimarker.com/biomarker/) to identify whether they were previously identified as candidate urinary disease biomarkers.

\section{Western blot}

Thirty micrograms of urinary protein from each sample $(n=4$ in each group) was loaded onto $10 \%$ SDS-PAGE gels and transferred to PVDF membranes with a transfer apparatus (Thermo Scientific, Pierce G2 Fast Blotter). After blocking in 5\% milk for $1 \mathrm{~h}$, the membranes were incubated with primary antibodies overnight at $4^{\circ} \mathrm{C}$. The primary antibodies used for validation included Haptoglobin (HPT) and Neutrophil collagenase (MMP8) (Abcam, USA). The membranes were then washed in TBST four times and incubated with secondary antibodies diluted $1: 5,000$ in a $5 \%$ milk solution for $1 \mathrm{~h}$ at room temperature. The immunoreactive proteins were visualized using enhanced chemiluminescence reagents (Thermo Scientific, USA). The protein signals were scanned with an ImageQuant 400TM Imager (GE Healthcare Life Sciences, Piscataway, NJ, USA), and quantified using the AlphaEaseFC system.

\section{Statistical analysis}

Statistical analysis was performed with the Statistical Package for Social Studies (PASW statistics, SPSS, version 18.0). Data for the body weight, urine volume, and biochemical indicators in urine were presented as the mean standard deviation. All of the parameters were tested for normalization, and comparisons of these data between the control and prednisone group were performed using Student's t-test. P-values of less than 0.05 were considered statistically significant.

\section{Results}

\section{Characterization of prednisone-treated rats}

To investigate the effect of prednisone treatment on the urine proteome, rats were treated with prednisone or saline for fourteen days. At baseline, no significant differences of body weight were observed between two groups (222.17 7.41 vs.224.33 5.01g, prednisone vs. control). Lower body weights were observed in rats receiving prednisone therapy compared with control rats on days 7 (245.83 9.62 
vs. $255.507 .04 \mathrm{~g})$ and 14 (279.50 10.84 vs. 292.33 9.27g). However, this difference was not statistically significant (Figure 1a).

Urine samples were collected within $8 \mathrm{~h}$ of intragastric administration in the two groups, and urine volumes and biochemical indicators were measured. As shown in Figure 1b, rat urinary volumes increased significantly after prednisone treatment compared
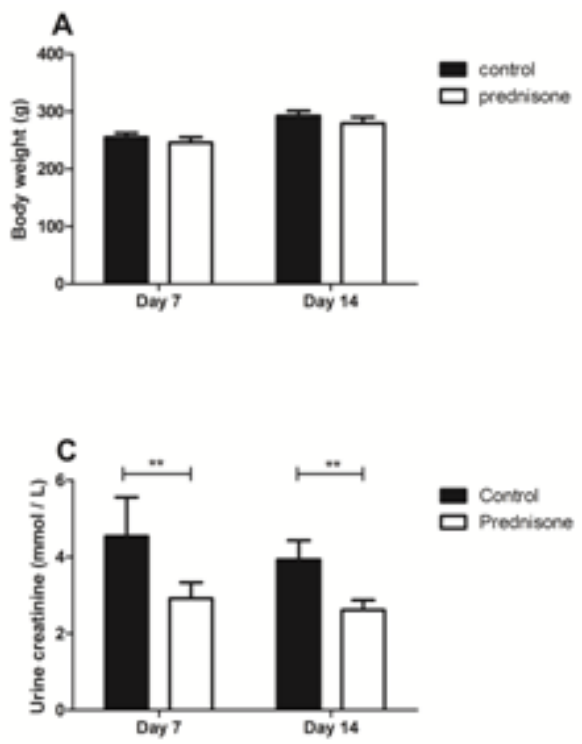

Figure I Body weights and urinary biochemical indicators in prednisone-treated and control rats

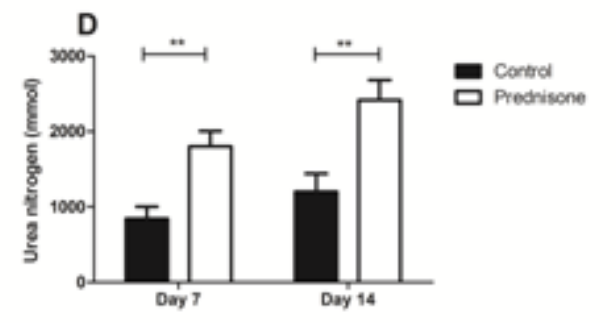

with controls (9.02 1.25 vs. $3.750 .96 \mathrm{ml}$, on day $7 ; 10.851 .70$ vs. $5.581 .67 \mathrm{ml}$, on day 14 , both $\mathrm{p}$-values $<0.01$ ). Meanwhile, the urine creatinine concentration was decreased in the prednisone group (Figure $1 \mathrm{c}, \mathrm{p}<0.05$ ). As shown in Figure 1d, the excretion of urea nitrogen was significantly increased in urine from the prednisone group (1800.69 203.88 vs.843.21 $156.86 \mathrm{mMol}$, on day 7; 2,417.41 265.41 vs. $1,204.81233 .58 \mathrm{mMol}$, on day 14 , both p-values $<0.01)$.

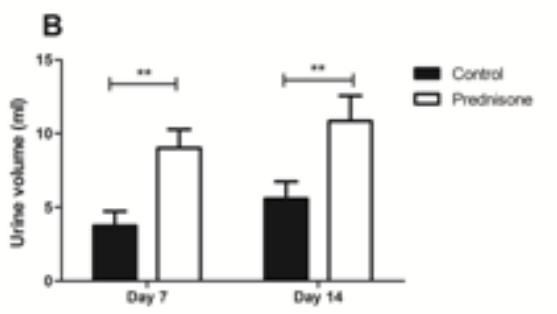

(A):The body weights of rats in the two groups on days 7 and 14 .

(B-D): Urine volumes, creatinine concentration and urea nitrogen levels in urine within $8 \mathrm{~h}$ of prednisone administration. The data represent the mean \pm standard deviation $\left(n=6\right.$ in each group, $\left.{ }^{* *} p<0.01\right)$. Student's t-test was used to assess whether the differences between the two groups were significant.

\section{Changes to the urine proteome after prednisone} administration

For proteomics analysis, ten urine samples were randomly selected from the prednisone and control groups on day 14. Using the labelfree quantification by the Progenesis LC-MS software, 523 urinary proteins were identified with a $1 \%$ false discovery rate (FDR) at the protein level. The criteria for identifying differentially expressed proteins included a fold change $>1.5$ and $\mathrm{p}$ value $<0.05$ between the two groups. Ultimately, 27 differentially expressed proteins were identified in urine with at least 2 unique peptides used for quantitation. Specifically, 12 proteins showed increased relative abundance, and 15 proteins showed decreased abundance (Table 1).

Table I Details of the identified urinary proteins altered by prednisone treatment

\begin{tabular}{|c|c|c|c|c|c|c|c|}
\hline \multirow{2}{*}{ Uniprot } & \multirow{2}{*}{ FC } & \multirow{2}{*}{ Description } & \multirow{2}{*}{$\mathbf{P}$} & \multirow{2}{*}{$\begin{array}{l}\text { Human } \\
\text { ortholog }\end{array}$} & \multirow{2}{*}{$\begin{array}{l}\text { IPA } \\
\text { Marker }\end{array}$} & \multicolumn{2}{|c|}{ Urinary protein biomarker database ${ }^{b}$} \\
\hline & & & & & & Biomarker-animal & Biomarker-human \\
\hline P02764 & 1.77 & Alpha-I-acid glycoprotein & 0.004 & P02763 & Yes & $\uparrow$ in DN & $\begin{array}{l}\uparrow \text { in TIDM, DN, renal AR, AKI, acute } \\
\text { appendicitis, vasculitis and pre- } \\
\text { eclampsia }\end{array}$ \\
\hline P05545 & 1.61 & Serine protease inhibitor $\mathrm{A} 3 \mathrm{~K}$ & 0.009 & POIOII & - & $\begin{array}{l}\downarrow \text { in acute renal } \\
\text { failure and nephrotic } \\
\text { syndrome }\end{array}$ & $\begin{array}{l}\uparrow \text { in T2DM, renal AR, non-small } \\
\text { cell lung carcinoma and acute } \\
\text { appendicitis }\end{array}$ \\
\hline P09006 & 2.42 & Serine protease inhibitor $A 3 N$ & 0.001 & POIOII & Yes & - & $\begin{array}{l}\uparrow \text { in T2DM, renal AR, non-small } \\
\text { cell lung carcinoma and acute } \\
\text { appendicitis }\end{array}$ \\
\hline P02780 & 2.66 & $\begin{array}{l}\text { Secretoglobin family } 2 \mathrm{~A} \\
\text { member } 2\end{array}$ & 0.053 & - & - & $\begin{array}{l}\downarrow \text { in nephrotic } \\
\text { syndrome }\end{array}$ & - \\
\hline P06866 & 2.08 & Haptoglobin & 0.047 & P00738 & Yes & $\begin{array}{l}\text { 个in nephrotic } \\
\text { syndrome }\end{array}$ & $\begin{array}{l}\uparrow \text { bladder transitional cell carcinoma, } \\
\mathrm{AKI}, \mathrm{DN} \text {, and T2DM }\end{array}$ \\
\hline P36374 & 2.01 & Prostatic glandular kallikrein-6 & 0.047 & - & - & $\downarrow$ in acute renal failure & - \\
\hline Q9EQV6 & 1.9 & Tripeptidyl-peptidase I & 0.001 & OI4773 & - & - & - \\
\hline
\end{tabular}


Table Continued....

\begin{tabular}{|c|c|c|c|c|c|c|c|}
\hline \multirow{2}{*}{ Uniprot } & \multirow{2}{*}{ FC } & \multirow{2}{*}{ Description } & \multirow{2}{*}{$\mathbf{P}$} & \multirow{2}{*}{$\begin{array}{l}\text { Human } \\
\text { ortholog }\end{array}$} & \multirow{2}{*}{$\begin{array}{l}\text { IPA } \\
\text { Marker }\end{array}$} & \multicolumn{2}{|c|}{ Urinary protein biomarker database ${ }^{b}$} \\
\hline & & & & & & Biomarker-animal & Biomarker-human \\
\hline O88766 & 1.69 & $\begin{array}{l}\text { Neutrophil collagenase } \\
\text { (MMP8) }\end{array}$ & 0.005 & P22894 & Yes & - & - \\
\hline P02782 & 2.79 & $\begin{array}{l}\text { Prostatic steroid-binding } \\
\text { protein } \mathrm{Cl}\end{array}$ & 0.038 & - & - & - & - \\
\hline O547I5 & $\mathrm{I} .85$ & $\begin{array}{l}\text { V-type proton ATPase subunit } \\
\text { SI }\end{array}$ & 0.001 & Q15904 & - & - & - \\
\hline Q9R0J8 & 1.51 & Legumain & 0.045 & Q99538 & - & - & - \\
\hline P84039 & 2.11 & $\begin{array}{l}\text { Ectonucleotide } \\
\text { Pyrophosphatase/ } \\
\text { phosphodiesterase family } \\
\text { member } 5\end{array}$ & 0.01 & Q9UJA9 & - & - & - \\
\hline P23680 & -1.68 & Serum amyloid P-component & 0.006 & P02743 & Yes & $\begin{array}{l}\uparrow \text { in anti-GBM nephritis } \\
\text { and lupus nephritis }\end{array}$ & $\uparrow$ in intestinal mucosal injury \\
\hline P04764 & -1.57 & Alpha-enolase & 0.011 & P06733 & Yes & - & $\downarrow$ in Dents disease \\
\hline P8I828 & $-1.6 \mid$ & Urinary protein 2 & 0.039 & - & - & $\begin{array}{l}\downarrow \text { in nephrotic } \\
\text { syndrome }\end{array}$ & - \\
\hline P8I827 & -1.68 & Urinary protein I & 0.038 & - & - & $\begin{array}{l}\downarrow \text { in nephrotic } \\
\text { syndrome and } \\
\text { glomerulonephritis }\end{array}$ & - \\
\hline P35444 & -1.62 & $\begin{array}{l}\text { Cartilage oligomeric matrix } \\
\text { protein }\end{array}$ & 0.011 & P49747 & Yes & $\uparrow$ in osteoarthritic & - \\
\hline P0I830 & -1.9 & Thy-I membrane glycoprotein & 0.036 & P04216 & Yes & - & $\uparrow$ in prostate cancer \\
\hline O35II2 & $-|.5|$ & CDI66 antigen & 0.004 & Q13740 & Yes & - & $\uparrow$ in TIDM \\
\hline P52590 & -1.99 & $\begin{array}{l}\text { Nuclear pore complex } \\
\text { protein Nup } 107\end{array}$ & 0.007 & P57740 & - & - & $\downarrow$ in IgA nephropathy \\
\hline PI5473 & -1.53 & $\begin{array}{l}\text { Insulin-like growth factor- } \\
\text { binding protein } 3\end{array}$ & 0.017 & PI7936 & Yes & - & $\uparrow$ prostate cancer \\
\hline PII030 & -1.56 & Acyl-CoA-binding protein & 0.029 & P07I08 & - & - & $\uparrow$ in Dents disease \\
\hline P97603 & -1.5 & Neogenin (Fragment) & 0.009 & Q92859 & - & - & - \\
\hline P80202 & -1.89 & Activin receptor type-IB & 0.046 & P36896 & - & - & - \\
\hline P08649 & -1.66 & Complement C4 & 0.019 & POC0L4 & - & - & - \\
\hline PI6310 & -1.58 & Growth hormone receptor & 0.039 & PI09I2 & - & - & - \\
\hline Q5FVR0 & $-|.5|$ & $\begin{array}{l}\text { T-cell immunoglobulin and } \\
\text { mucin domain-containing } \\
\text { protein } 2\end{array}$ & 0.02 & - & - & - & - \\
\hline PI4046 & $-1.7 \mid$ & Alpha-I-inhibitor 3 & 0.003 & POI023 & - & - & - \\
\hline Q0I205 & $-|.6|$ & $\begin{array}{l}\text { 2-oxoglutarate dehydrogenase } \\
\text { complex component E2 }\end{array}$ & 0.026 & P36957 & - & - & - \\
\hline
\end{tabular}

${ }^{\mathrm{a}}$ Disease biomarkers filtered using IPA. 'Urinary disease biomarkers from the Urinary Protein Biomarker Database identified in animal models and human diseases.

Abbreviations: TIDM, type I diabetes;T2DM, type 2 diabetes; DN, diabetic nephropathy;AKI, acute kidney injury;AR, allograft rejection

To identify major diseases and bio-functions of differential proteins involved, Ingenuity Pathway Analysis (IPA) Software was used for canonical function enrichment analysis. As shown in Figure 2 , the principal diseases affected by the differential proteins included the inflammatory response, metabolic disease and cancer. The principal bio-functions of the differential proteins included cell death and survival, protein metabolism (degradation and synthesis), lipid metabolism, amino acid metabolism and carbohydrate metabolism.

Two up-regulated proteins (Haptoglobin and Neutrophil collagenase) identified in our proteomic study with commercially available antibodies were selected to be validated by semi-quantitative western blot analysis (Figure 3 ). The changes of both proteins in Western Blot experiment were consistent with the LC-MS/MS results. 


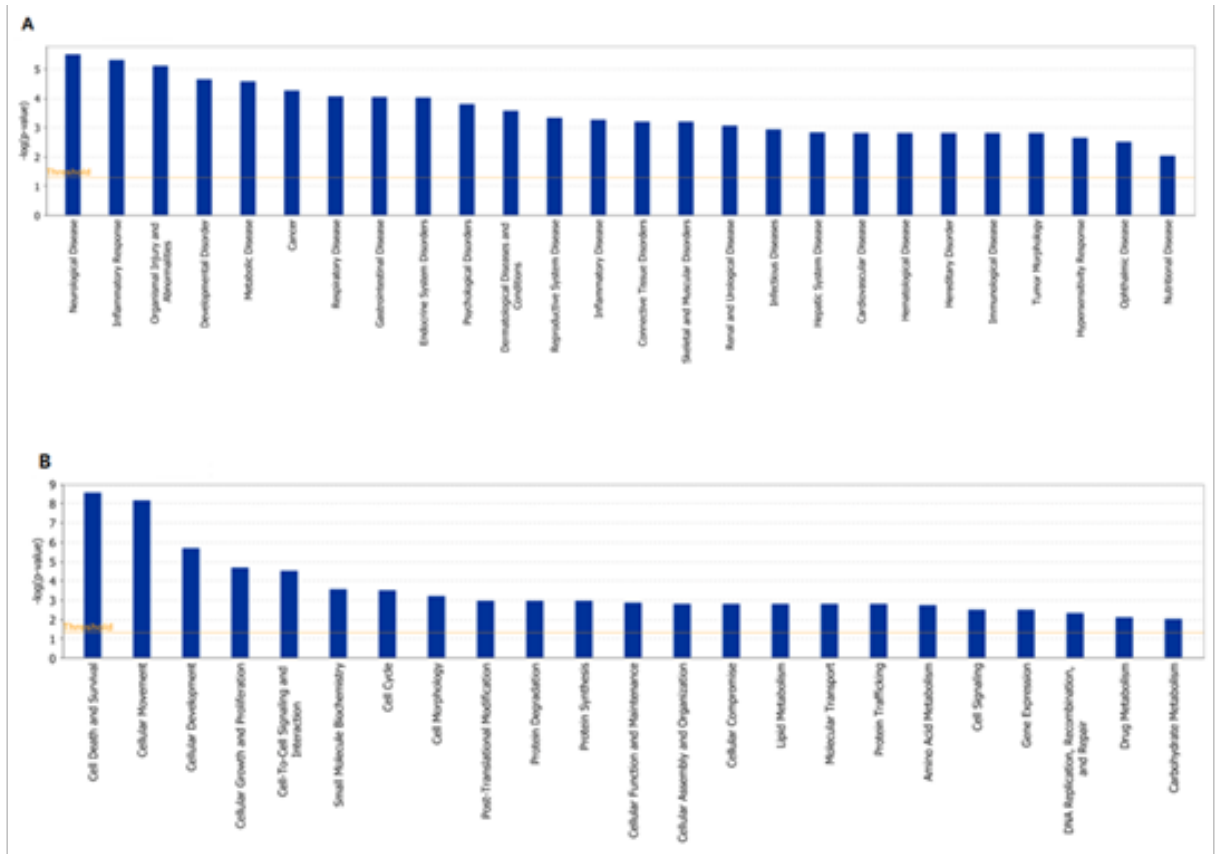

Figure 2 Analysis of principal diseases and bio-functions in which the differentially expressed proteins participate using IPA.

i. Significance values were calculated based on Fisher's right tailed exact test, and the -log(p-value) was calculated and is displayed on the $y$-axis of the bar chart. The taller the bar, the more significant the pathway effect.

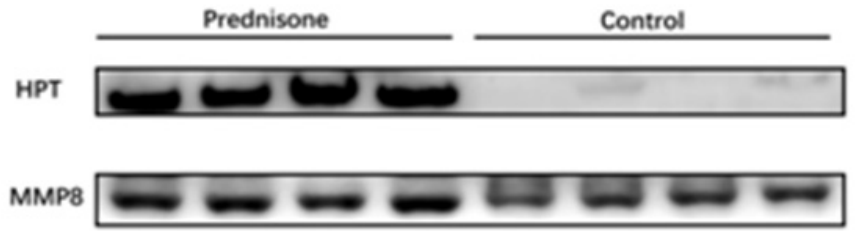

Figure 3 Western blot analysis of HPT and MMP8 in the urine samples after prednisone administration.

A total of eight samples were used for validation ( $n=4$ in each group). The intensity of each protein before and after prednisone administration was analyzed by Mann-Whitney test.

\section{Effects of prednisone treatment on relevant disease biomarkers in urine}

Using the biomarker filtering tool in IPA, 10 differential proteins were identified as disease biomarkers. Because orthologs have similar bio-functions across different species, we converted the rat proteins to human proteins, and 23 differential proteins had human orthologs. When the selected differential proteins and their human orthologs were searched against the Urinary Protein Biomarkers Database, 16 proteins were annotated as candidate urine biomarkers in previous studies. The expression trends of these biomarkers in various diseases are shown in Table 1. The expression of 8 differential proteins were completely reversed after prednisone treatment compared with their expression in specific pathological conditions, including Secretoglobin family 2A member 2, Prostatic glandular kallikrein-6, Serum amyloid P-component, Cartilage oligomeric matrix protein, Thy-1 membrane glycoprotein, CD166 antigen, Insulin-like growth factor-binding protein 3, and Acyl-CoA-binding protein. Meanwhile, the expression of 7 differential proteins in our study after prednisone treatment were similar to levels in specific disease conditions, including Alpha-1-acid glycoprotein, Serine protease inhibitor A3N, Haptoglobin, Alpha-enolase, Urinary protein 1, Urinary protein 2, and Nuclear pore complex protein Nup107.

\section{Discussion}

In this study, we evaluated the possible impact of prednisone treatment on the urinary proteome and related disease biomarkers in a rat model. The doses of prednisone used in this study were according to a previous study to mimic clinical practices. ${ }^{10}$ Changes of body weights and urine biochemical indicators in prednisone-treated rats were consistent with pharmacological effects of prednisone. Reduced body weight might be due to growth inhibition caused by glucocorticoid treatment. ${ }^{11}$ The increased urine volume and decreased creatinine concentration after prednisone treatment were induced by the diuretic effect of glucocorticoids. Additional, prednisone treatment induces an overall catabolic protein response and accelerate protein breakdown, ${ }^{9}$ which can lead the body to dispose of excess nitrogen waste as urea in urine.

The strong association between prednisone treatment and protein metabolism may also contribute to the changes in the urinary proteome. Several differential proteins identified in current study were reported to be regulated by glucocorticoids in previous studies, such as the serine protease inhibitor A3N, ${ }^{12}$ alpha-1-acid glycoprotein, ${ }^{13} \mathrm{mMP} 8,{ }^{14}$ growth hormone receptor ${ }^{15}$ insulin-like growth factor-binding protein $3^{16}$ and acyl-CoA-binding protein, ${ }^{17}$ suggesting the reliability of the proteomics results. Moreover, two differentially expressed proteins (Haptoglobin and Neutrophil collagenase) in our study were further validated by Western Blot. The results suggested these urinary proteins were glucocorticoid responsive, similar to thrombospondin- $1,{ }^{18}$ which has potential clinical utility as a glucocorticoid activity biomarker in urine.

Prednisone is widely used in clinical practice based on its potent anti-inflammatory, immunosuppressive and anti-cancer effects. The enriched bio-function of differential proteins was consistent with the regulatory actions of prednisone in inflammation, immunity, metabolism and cancer, suggesting that the pharmacological effects of prednisone were reflected in the urine proteome after prednisone administration. As a good biomarker source, urine has the potential 
to reveal many types of changes (physiological, pathological, and pharmacological changes) in the body. Our results suggested the application of urinary proteomics may assist in identification of noninvasive biomarkers to detect drug efficacy in future studies.

One important issue in the use of urine to detect biomarkers is that many factors can affect the urine proteome. Previous studies showed that several common physiological factors influence the urine proteome. ${ }^{1}$ Compared with physiological factors, pharmacological agents are more important factors that should also be taken into consideration. In clinical practice, drugs can reverse the disease process and are very likely to have a significant impact on the urinary proteome and related disease biomarkers. Of note, physiological factors can often be well-matched for biomarker research. However, due to ethical issues, it is impossible to halt drug treatment in patients during urine collection or to give healthy volunteers drugs they do not need. Knowing the impact of drugs on the urine proteome can help us eliminate interference when detecting real disease biomarkers in urine. In previous studies, anticoagulants ${ }^{19}$ and the $\alpha 1$-adrenergic receptor antagonis $\mathrm{t}^{20}$ were reported to influence the urine proteome and related biomarkers. Likewise, in the current study, 27 proteins were differentially expressed after prednisone treatment, and 16 of these proteins were reported as disease biomarkers, suggesting the potential impact of prednisone treatment on urine biomarker identification via proteomics approaches.

Notably, the expression of some candidate biomarkers were completely reversed after prednisone treatment compared with their expression in specific pathological conditions (Table 1). These proteins might serve as candidate therapeutic biomarkers for monitoring treatment effectiveness or reflecting glucocorticoid sensitivity. For example, up-regulated serum amyloid $\mathrm{P}$ (SAP) in the urine was identified as a biomarker of anti-glomerular basement membrane disease and lupus nephritism, ${ }^{21}$ and increased cartilage oligomeric matrix protein (COMP) in urine was observed in osteoarthritis. ${ }^{22}$ Both proteins were downregulated in urine after prednisone treatment in our study; thus, these proteins might indicate the effectiveness of glucocorticoids in treating these diseases. Thus, previous studies with patients receiving drug treatments might have underestimated or not identified changes to candidate disease biomarkers. By contrast, the expression of several candidate biomarkers in our study after prednisone treatment was similar to levels in specific disease conditions. These changes might not be relevant to the treatment effects of prednisone for these diseases and might even be erroneously considered disease biomarkers if the drug effect was not considered. Therefore, the effects of prednisone treatment should be taken into consideration in future disease biomarker studies.

In summary, prednisone is a widely prescribed drug in clinical practice, and its effects are strongly associated with protein metabolism. In this study, the significant changes to protein abundance identified by mass spectrometry suggested a large impact of prednisone treatment on urine proteome and related urinary biomarkers. Therefore, changes to the urine proteome and disease biomarkers from prednisone treatment should be considered in future biomarker studies.

\section{Acknowledgements}

This work was supported by the National Key Research and Development Program of China (2016YFC1306300); the National Basic Research Program of China (2013CB530805); Beijing Normal University (11100704); and Beijing Natural Science Foundation (Nos. $7173264,7172076)$. The raw mass spectrometry data are available in the Figshare repository (https://doi.org/10.6084/m9.figshare.3486035. v1).

\section{Conflict of interest}

The authors declare that there is no conflict of interests regarding the publication of this paper.

\section{References}

1. Wu J, Gao Y. Physiological conditions can be reflected in human urine proteome and metabolome. Expert Rev Proteomics. 2015;12(6):623-636.

2. Thongboonkerd V, Malasit P. Renal and urinary proteomics: current applications and challenges. Proteomics. 2005;5(4):1033-1042.

3. Guo Z, Zhang Y, Zou L, et al. A Proteomic Analysis of Individual and Gender Variations in Normal Human Urine and Cerebrospinal Fluid Using iTRAQ Quantification. PLoS One. 2015;10(7):e0133270.

4. Bakun M, Senatorski G, Rubel T, et al. Urine proteomes of healthy aging humans reveal extracellular matrix (ECM) alterations and immune system dysfunction. Age. 2014;36(1):299-311.

5. Castagna A, Olivieri O, Milli A, et al. Female urinary proteomics: New insight into exogenous and physiological hormone-dependent changes. Proteomics Clinical Appl. 2011;5(5-6):343-353.

6. Kohler M, Walpurgis K, Thomas A, et al. Effects of endurance exercise on the urinary proteome analyzed by $2-\mathrm{D}$ PAGE and Orbitrap MS. Proteomics Clinical Appl. 2010;4(5):568-576.

7. Haniff AN, Gam LH. Identification of urinary protein biomarkers for tobacco smoking. Biotechnol Appl Biochem. 2016;63(2):266-272.

8. van Staa TP, Leufkens HG, Abenhaim L, et al. Use of oral corticosteroids in the United Kingdom. QJM. 2000;93(2):105-111.

9. Rose AJ, Herzig S. Metabolic control through glucocorticoid hormones: an update. Mol Cell Endocrinol. 2013;380(1-2):65-78.

10.Kedzierska K, Sporniak-Tutak K, Sindrewicz K, et al. Effects of immunosuppressive treatment on protein expression in rat kidney. Drug Des Devel Ther. 2014;8:1695-1708.

11. Stikkelbroeck NM, Van't Hof-Grootenboer BA, Hermus AR, et al. Growth inhibition by glucocorticoid treatment in salt wasting 21 hydroxylase deficiency:in early infancy and (pre)puberty. $J$ Clin Endocrinol Metab. 2003;88(8):3525-3530.

12. Nilsson LN, Das S, Potter H. Effect of cytokines, dexamethasone and the A/T-signal peptide polymorphism on the expression of alpha(1) antichymotrypsin in astrocytes: significance for Alzheimer's disease. Neurochem Int. 2001;39(5-6):361-370.

13. Fournier $\mathrm{T}$, Bouach $\mathrm{N}$, Delafosse $\mathrm{C}$, et al. Inducible expression and regulation of the alpha 1-acid glycoprotein gene by alveolar macrophages: prostaglandin E2 and cyclic AMP act as new positive stimuli. J Immunol. 1999;163(5):2883-2890.

14. Muratore CS, Harty MW, Papa EF, et al. Dexamethasone alters the hepatic inflammatory cellular profile without changes in matrix degradation during liver repair following biliary decompression. J surg Res. 2009;156(2):231-239.

15. Vottero A, Kimchi-Sarfaty C, Kratzsch J, et al. Transcriptional and translational regulation of the splicing isoforms of the growth hormone receptor by glucocorticoids. Horm Metab Res. 2003;35(1):7-12.

16. Baxter RC. The role of insulin-like growth factors and their binding proteins in tumor hypoglycemia. Horm Res. 1996;46:195-201.

17. Compere V, Ouellet J, Luu-The V, et al. Role of androgens and glucocorticoids in the regulation of diazepam-binding inhibitor mRNA levels in male mouse hypothalamus. Brain Res. 2006;1119(1):50-57. 
18. Barclay JL, Petersons CJ, Keshvari S, et al. Thrombospondin-1 is a glucocorticoid responsive protein in humans. Eur $J$ Endocrinol. 2016;174(2):193-201.

19. Li M, Zhao M, Gao Y. Changes of proteins induced by anticoagulants can be more sensitively detected in urine than in plasma. Sci China Life sci. 2014;57(7):649-656.

20. Zhao M, Wu J, Gao Y. The Specific alpha1-Adrenergic Receptor Antagonist Prazosin Influences the Urine Proteome. PLoS One. 2016;11(10):e0164796.
21. $\mathrm{Wu} \mathrm{T}, \mathrm{Fu} \mathrm{Y}$, Brekken $\mathrm{D}$, et al. Urine proteome scans uncover total urinary protease, prostaglandin D synthase, serum amyloid $\mathrm{P}$, and superoxide dismutase as potential markers of lupus nephritis. J Immunol. 2010;184(4):2183-2193.

22. Misumi K, Tagami M, Kamimura T, et al. Urine cartilage oligomeric matrix protein (COMP) measurement is useful in discriminating the osteoarthritic Thoroughbreds. Osteoarthritis Cartilage. 2006;14(11):1174-1180 